\title{
Transformation as an act of denudation: A response to Petro du Preez, Shan Simmonds and Anné Verhoef
}

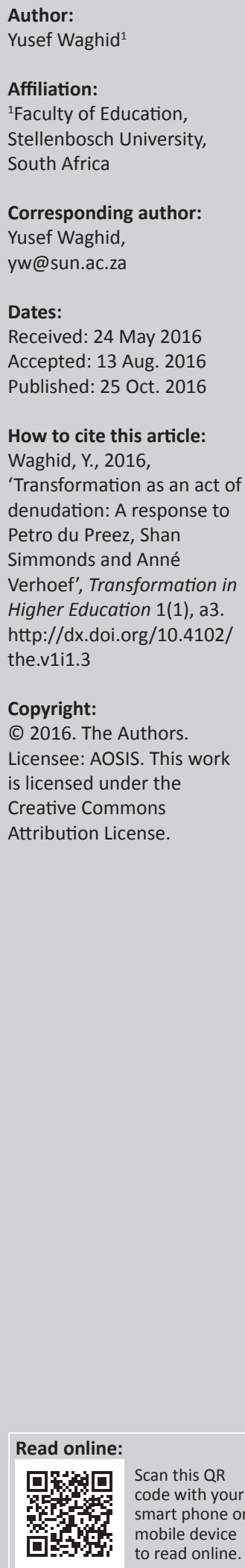

\begin{abstract}
Higher education transformation in South Africa, as correctly argued by Petro du Preez, Shan Simmonds and Anné Verhoef, should become more 'fluid [and] open-ended'. However, even more fluidity and open-endedness might not necessarily be sufficient in enacting transformation in the higher education realm. Consequently, in this article I argue in defence of a form of denudification of higher education that would impact transformation with an unrestrained openness and concealment whereby the unexpected will remain in potentiality. It is hoped that higher education transformation in South Africa would become more open and credible as has been achieved hitherto.
\end{abstract}

\section{Introduction}

Petro du Preez, Shan Simmonds and Anné Verhoef's article entitled: 'Rethinking and researching transformation in higher education: A meta-study of South African trends' is a credible analytical attempt to foreground transformation patterns that occurred in South African higher education over the past decade (2005-2015). From my reading of their insightful article, I have conjured up three main inferences: Firstly, their etymological attempt to clarify quite lucidly what constitutes the notion of transformation invariably resonates with previous understandings of the notion in relation to some form of permanent conceptual change - and in this sense, their own clarification does not appear to be novel; secondly, although their analysis identifies trends in the transformation of higher education in South Africa as a corollary of their reliance on the South African Journal of Higher Education exclusively, their own attempts suffer an educational bias - which they paradoxically envisage to refute; and thirdly, their bold assertion to rethink higher education transformation along the lines of some 'fluid and open-ended construct' seems to remain truncated as their proffering quite correctly leaves the discourse of higher education transformation unresolved and 'open-ended'. In this response, I envisage to extend their claim beyond a mere call for 'open-endedness'. Rather, in reference to Giorgio Agamben's notion of 'denudation' whereby it is argued that forms of human engagement can become substantively transformative if enacted through an unconcealed disclosedness, that is, an unveiling of the self in which visibility and presence (nudity) hold sway. In other words, inasmuch as higher education should be conceived as an open-ended discourse - a view advocated by Du Preez, Simmons and Verhoef - humans ought to disclose themselves to others in order for the encounter to remain transformative. And, when such a form of transformative engagement assumes a form of denudation, the possibility is always there that human action will be enacted through an unveiling of the self that is infinitely free of secret. Hopefully then, educational transformation will be more unconstrained and unrestricted by that which might be otherwise contained.

\section{Democratic iterations and reciprocity as forms of transformative human engagement}

By way of introduction, much has been written about the notion of transformative human engagement in relation to dialogical forms of human action. Firstly, Seyla Benhabib (2011) offers an account of deliberative engagement whereby human beings listen to one another with the aim to reflexively talk back to one another - that is, to take one another's points of view into iterative scrutiny. In her words, ' $[b]$ y democratic iterations I mean complex processes of public argument, deliberation, and exchange through which universalist rights claims are contested and contextualized, invoked and revoked ... in the associations of civil society' (Benhabib 2011:129). In other words, human beings do not just deliberate to allow one another an opportunity to critically respond to one another. Rather, their interactions are meant to provoke one another 
to think and act differently - that is, to see the point of their engagements in a contested atmosphere without being remiss of treating one another with dignity. In this sense, humans are self-interpreting beings who have 'the capacity to initiate action and opinion to be shared by others ...' (Benhabib 2011:129). Thus, following Benhabib, transformative engagement is not merely associated with enframing people's collective existence; it is also an enlargement of people's moral perspectives 'in virtue of their humanity simpliciter' (Benhabib 2011:75). Secondly, Amy Gutmann and Dennis Thompson (2004:178) elucidate collective human co-existence on the basis that 'people should be treated as free and equal citizens'. For them, transformative engagement is explicitly concerned with people seeking moral agreement when they can engage in/about public policy through deliberation, and 'maintaining mutual respect when they cannot [reach agreement]' (Gutmann \& Thompson 2004:178). This kind of democratic reciprocity 'asks citizens to try to justify their political views to one another and to treat with respect those who make good-faith efforts to engage in this mutual enterprise even when they cannot resolve their disagreements' (Gutmann \& Thompson 2004:179). The point is, democratic engagement (reciprocity) calls for people to equally engage with one another in an atmosphere of mutual respect even if they vehemently disagree. This kind of dignified relationship amongst humans engaged in democratic reciprocity is cultivated through an 'open-mindedness ... [and] respect for differing points of view without either endorsing them as clearly correct or rejecting them as clearly incorrect' (Gutmann \& Thompson 2004:185). In this way, through transformative democratic engagement, people not only retain their dignity but also the possibility for reasonable agreement and disagreement. That is, democratic reciprocity does not require moral detachment from one another. Instead, democratic reciprocity would judge injustice harshly and praise just actions (Gutmann \& Thompson 2004:186). By implication, people engaged in democratic reciprocity will not find themselves detached from one another because moral disagreement should not be a reason for excluding others from the deliberation.

\section{Towards an expanded view of transformative democratic engagement through humaneness}

David T. Hansen (2011:22-23) posits that central to any form of educational experience, notwithstanding a transformative and democratic one is a form of humaneness (referred to by Benhabib, and Gutmann and Thompson, respectively, as dignity and respect). For Hansen (2011:22), humaneness is tantamount to 'practicing justice towards others' in that it 'privileges learning from others over resolving tensions to one's personal satisfaction'. Whereas Benhabib, and Gutmann and Thompson seemingly advocate an understanding of humaneness as a democratic virtue whereby people are mutually engaged in deliberative iterations and reasonable agreements and disagreements, Hansen (2011:22) elucidates humaneness as 'a mode of work rather than a final achievement' that involves 'learning from others'. By the latter he means a capacity to wait and see, listen and a desire to understand the other (Hansen 2011:23). In this way, humaneness implies a democratic etiquette whereby human beings are not in isolation from one another but in perpetual communication. In other words, humans do not just wait for agreement to be achieved but they engage humanely in democratic action (Hansen 2011:28). And in enacting oneself humanely in relation to others, humans pursue 'a reflective openness to the new with reflective loyalty to the known' (Hansen 2011:32) - a view that can extend the etymological take on transformation enunciated by Du Preez and others. My interest is in Hansen's depiction of humaneness as an enactment of democratic engagement such that it (humaneness) can cultivate a reflective openness to the new and a reflective loyalty to the known. I am attracted to democratic engagement as the cultivation of humaneness for two reasons: In the first instance, learning from others through a reflective openness to the new is a recognition that a democratic and transformative encounter can be uncertain which implies that the unexpected can happen. In other words, human relations in an uncertain world cannot always be perfectly planned, rationalised and predicted. Currently in South Africa, the ruling African National Congress could not have anticipated or predicted that its political hegemony would be seriously challenged by members of its own party considering the role the party has played in the demise of the apartheid regime. Consequently, one finds that Hansen (2011:54-55) posits that '[d]eliberative ways of listening, speaking, waiting, reading, writing, memorizing, repeating and judging ... [should be attentive to] different points of view and a more patient approach to conflicts of interests and concern'. Put differently, being reflectively open to the new implies that democratic encounters should remain sensitive to humaneness; and second, being reflectively loyal to the known implies that a more lucid understanding of what is already known would invariably enhance one's understanding of a particular situation. For instance, if it is already known that democratic encounters include rather than exclude people, then being reflectively loyal to such an encounter means that one can be open to more innovative ways of securing inclusion. Thus, by being reflectively open to the new and reflectively loyal to the known, one might avoid doing harm to others in a democratic encounter - that is, one would have developed a sense of self-control which is not dismissive of what other have to say 'thereby making possible humane ways of dwelling together' (Hansen 2011:55).

However, being reflectively open to the new and reflectively loyal to the known implies other humans need to open themselves up to one in order for one to learn from them. But, for a democratic (and by implication a transformative) encounter to be mutually open, one also needs the self to open up to others. Put differently, one needs to disclose oneself to others in order for the latter to openly engage with one. 
However, it seems as if democratic iterations and democratic reciprocity might not be sufficient to elicit more open and unconstrained forms of human (inter)action. That is, people can deliberate iteratively and engage one another reciprocally but this does not necessarily mean that they would always exhibit a humaneness towards one another. For instance, after the popular uprisings of masses of people against dictatorships on the African continent (e.g. in Egypt, Tunisia and Libya) - referred to commonly as the Arab Spring several governments that initially deliberated iteratively and reciprocally with other members of civil society became even more inhumane towards any form of public dissent. My contention is unless democratic encounters were to take the form of denudification whereby people disclosed themselves to one another equally and substantively, such encounters will remain truncated and possibly become more prejudiced towards exclusion. The point is that unless people open themselves up substantively to one another, any form of tenable inclusion might not ensue, that is, transformation might be thwarted. For instance, in contemporary South African higher education, many institutional responses to student protestations vis-à-vis the exorbitant increase in student fees have been belligerent and often dismissive of students' legitimate concerns. It seems as if many universities in the country have already succumbed to neoliberal dictates of a globalised world economy whereby an increase in profit is deemed to be significant enough in shaping higher education. And, those students who are unable to afford higher education and contend with fees hikes are simply be ignored by university authorities. This apparent lack of regard to engage students deliberatively in a denudificated manner is simply symptomatic of a reluctance on the part of some university authorities to address legitimate student concerns in a democratically risk-full manner.

Inow turn to Giorgio Agamben for a perspective on denudation with the possibility of people engaging in democratic and transformative encounters, becoming more open and prepared to take risks.

In Defence of Denudation: Democratic and Transformative Engagement as an Unconcealed Disclosedness of the Human Self, Agamben (2011:81) introduces the notion of nudity in relation to human action. In his words, 'to know nudity is not to know an object but only an absence of veils, only a possibility of knowing'. In other words, nudity is a condition of 'disclosedness' (al-letheia), that is, 'unconcealment' without which knowledge would not be possible (Agamben 2011:81). What follows, that unless people do not engage with nudity in democratic and transformative encounters, the possibility that they would learn from one another would be very unlikely. Again, nudity or denudation is a condition of 'pure visibility and presence' whereby no secret is concealed (Agamben 2011:81). So, for Agamben (2011:84, 86), the nudity of the human body is its image of an unveiled appearance which is 'infinitely free of secret' - an appearance that exhibits its own vacuity and that allows the inapparent to take place. Put differently, nudity or denudation 'lets the absence of secrets be seen', which means it expresses only a 'letting-beseen' (Agamben 2011:89). When nudity unveils secrets of the human self, then a point is reached in which 'clarification is no longer possible' because an appearance has been exhibited 'beyond all mystery and all meaning' (Agamben 2011:89, 90). Now in relation to democratic and transformative encounters, such a form of engagement is only subjected to denudation when the interaction between humans unveils what is mysterious in the sense that the covert is opened up to humans engaged in the interaction. Here, the unveiling of the strange requires of humans to take risks on the basis of disclosedness and demystification. That is, risk taking increases when the mysterious is on the verge of being denudated. And, when the self experiences moments of denudation where nothing is concealed or censored, where secrets of the self have been unmasked, democratic and transformative engagement becomes open and unrestrained - that is, it is enveloped by a 'pure appearance' or 'absence of secrets' (Agamben 2011:90). How else can democratic engagement be substantively open if human thought in and about particular situations is not unconcealed or unveiled? The point I am making is that only a demystified form of democratic engagement would have deepened the risks human would have taken to elicit unconstrained encounters where nothing is held back and where human thought has been made transparent and accessible to all others. And, the possibility that human action can unveil mysterious meanings that can enhance people's interactions (and by implication their risk taking) would only contribute towards their intimacy - that is, their knowability (nudity) in sustaining unconstrained forms of democratic engagement.

To take a risk is tantamount to disclosing something that would otherwise have remained concealed. So, when one takes a risk, one divulges (unveils) what would otherwise have remained veiled or held back from others. And, unveiling one's nudity is an act of exposing what would otherwise have remained covered. Hence, to take a risk implies denudifying oneself. Inasmuch as risk taking is associated with disclosing oneself, so the Agambenian notion of rhythm is linked to a visible presence that assigns to a nude image its 'flows in time', that is, its 'movement' (Agamben 2004:99). For Agamben, this movement or 'eternal flow' of rhythm gives to risk taking 'a stop, an interruption in the incessant flow ... [that] gives and reveals the particular status, the mode of presence proper to the work of art [nude image] or the landscape we have before our eyes' (Agamben 2004:99). Agamben goes on to assert that once being 'arrested' by nudity means 'both to hold back, to suspend, and to hand over, to present, to offer' (Agamben 2004:100). What follows from the aforementioned, like risk taking, rhythm 'gives and holds back' (Agamben 2004:100). So, when a nude image presents itself to others, it gives and holds back - that is, nudity is subjected to a rhythmic movement of disclosure and retention. Put differently, denudification involves a rhythmic flow of movement whereby the image presents itself to the one witnessing the image - that is, the image is disclosed or unconcealed to others. Concomitantly, with the 
unveiling of the nude image, the witnesses to the image looks at what is discernible with moments of imperceptibility - that is, as if the nude image is at times not visible because of an interruption encountered because of what the witness is confronted with.

In conclusion, inasmuch as Du Preez and others' analytical effort to make higher education transformation in South Africa more responsive to fluidity and open-endedness, they somehow seem to capitulate to the taken-for-granted notion that higher education transformation ought to be rethought. Of course, this is correct. But then, if higher education were to become more transformative and remain in potentiality, it has to be thought of differently. It is in this regard that it might just be apposite to rethink higher education transformation vis-à-vis denudification!

\section{Acknowledgements Competing interests}

The author declares that he has no financial or personal relationships that may have inappropriately influenced him in writing this article.

\section{References}

Agamben, G., 2004, The man without content, transl. G. Albert, Stanford University Press, Stanford, CA.

Agamben, G., 2011, Nudities, transl. D. Kishik \& S. Pedatella, Stanford University Press, Stanford, CA.

Benhabib, S., 2011, Dignity in adversity: Human rights in troubled times, Polity Press, Cambridge.

Gutmann, A. \& Thompson, D., 2004, Why deliberative democracy?, Princeton University Press, Princeton, NJ.

Hansen, D.T., 2011, The teacher and the world: A study of cosmopolitanism as education, Routledge, London. 